Boise State University

ScholarWorks

Sociology Faculty Publications and Presentations

Department of Sociology

$1-1-2011$

\title{
Sentencing Outcomes of Convicted Child Sex Offenders
}

Steven Patrick

Boise State University

Robert Marsh

Boise State University 


\title{
Sentencing Outcomes of Convicted Child Sex Offenders
}

\author{
Steven Patrick and Robert Marsh \\ Boise State University
}

\begin{abstract}
This research examines the sentencing outcomes of convicted child sexual offenders from data collected over an eight year period. Multiple regression and nominal log linear regression are used to examine length of prison sentence, length of probation sentence, and whether or not the convicted offender is actually sent to prison or to probation. While many independent variables appear to be related to sentence outcome, they fall into three categories: characteristics of the offender, characteristics of the victim, and characteristics of the crime. Additionally, while many variables appear related at the bivariate level, when multivariate analysis is applied, fewer variables remain significant and these are mostly from the characteristics of the offense.
\end{abstract}

Keywords: child sexual abuse, sentencing, prison, probation

Many myths exist about those convicted of CSA and one is that all those convicted of felony CSA go to prison. In fact, less than a third of those convicted of CSA (28.7\%) are sent to prison (Marsh, Patrick, \& Hopfenbeck, 20012007). Understanding why individuals are sent to prison or probation and for how long is a topic of interest that can not only help us understand the outcomes of CSA sentencing but also help dispel one of the myths of CSA.

\section{Literature Review}

While there are numerous studies of the correlates of sentencing outcomes in general, there are few that focus on convicted child sex offenders (Austin \& Krisberg, 1985; Zatz \& Hagan 1985). In addition, while there have been numerous studies on sentencing, there is great variation in estimates of sentence length (Patterson \& Preston, 2008), resulting in a need for more research on this subject.

What we can do with child sex offenders can vary greatly from community protection to sex offender treatment (Petrunik \& Deutschmann, 2008). The United States has focused more heavily on the punitive end of this spectrum, resulting in large numbers of offenders being incarcerated for long periods and virtually all being labeled for life through offender registration programs (Greenfeld, Beck, \& Gilliard, 1996; Whitman, 2007). Research shows that those labeled are at greater risk for recidivism (Chiricos, Barrick, Bales, \& Bontrager, 2007) and have lower success rates after release (Weiman, 2007). Conversely, while growing, treatment of child sex offenders has historically been minimal. While all child sex abusers are supposed to receive sex offender evaluations, and these are seen as important in informing sentencing (Bonta, 2007), many still do not receive these evaluations in a timely manner (Marsh et al., 2001-2007).

There are basically two general outcomes for conviction of any offender convicted of CSA: incarceration or release under supervision. CSA is considered such a heinous crime that a number of states have enacted civil confinement laws for repeat violent offenders (Lucken \& Bales, 2008; Quinn, Forsyth, \& Mullen-Quinn, 2004). Even without empirical support, lawmakers continue to increase the penalties for CSA (Cohen, \& Jeglic, 2007). Mandatory sentencing, whether for sex offenses or other types of crime, ignores important considerations and results in higher incarceration rates than are necessary (Marvell, \& Moody, 1996; Mauer, 2007) but appears to do nothing to reduce crime rates (Doob, \& Webster, 2003; Kovandzic, Sloan, \& Vieraitis, 2004). Reports in general show that those released under parole are less likely to recidivate when compared to those who max out their sentence (Schlager \& Robbins, 2008). This demonstrates that in most cases supervising convicted offenders in the community is beneficial to community safety. While child sex offenders are often seen as predatory by nature, recidivism for child sex offender is often lower than for other types of offenders (Patrick \& Marsh, 2009). Continuing research shows that predictive assessments, including sex offender evaluations, have validity in predicting recidivism for violent crimes (Loza, MacTavish, \& Loza-Fanous, 2007). 
Even with the cultural view that all child sex offenders are evil and should be locked away, there is still wide variation in the sentencing of all offenders regardless of crime or criminal mandates (minimum sentencing or sentencing guidelines)(Crow \& Gertz, 2008; Cullen, Smith, Funk, \& Haaf, 2000). Research indicates that characteristics of the offense such as forced rape especially of victims under 12., repeat offenders, and certain minority groups are more likely to receive maximum sentences (Demuth, \& Steffensmeier, 2004; Ulmer, Kurlychek, \& Kramer, 2007). Other research shows that characteristics of the crime and victim, seriousness of offense, and victim age affect the length of sentence for child sex offenders (Faller, Birdsall, Vandervort, \& Henry, 2006). This speaks to the need to study as widely as possible the correlates of sentencing outcomes.

The purpose of this study is to better understand the determinants of incarceration and sentence length of those convicted of CSA. Factors that may play an important part in determining sentencing include characteristics of the offender and the victim and the actual circumstances of the offense. Our system of justice is assumed to be blind. If characteristics of the offender and victim determine the outcome of those convicted, then justice may not be blind. Alternatively, if characteristics of the offense appear to predominate in the sentencing outcomes then justice does appear to ignore personal characteristics.

\section{Methods}

Data for this research were collected annually as part of a state mandated census of felony cases of CSA in the State of Idaho. Members of the research team traveled to every county examining the court records to obtain data for the annual report. These data were collected at the end of the fiscal year for the preceding year. This method of data collection resulted in significant missing data, as many of the cases had not reached final resolution when the data were collected. Prior analysis has shown that those cases reaching conclusion, mostly those cases filed early in the fiscal year, are not different from those cases not reaching conclusion, mostly those cases filed late in the fiscal year (Patrick \& Marsh, 2009).

Data for this analysis were taken from the 2001 through 2007 data sets (Marsh et al., 2001-2007). A total of 1,069 cases from these 7 years were coded as convicted through plea agreement or trial (over $80 \%$ through plea bargain). Those pending trial, dismissed, or acquitted were removed. Those convicted but pending sentencing or placed on retained jurisdiction are included in the analysis. Those that do not serve actual prison time can be sentenced under Idaho Statute Title 19, 2601 Suspension of Judgment and Sentence, which states,

Whenever any person shall be convicted, or enter a plea of guilty in any district court of the state of Idaho, of or to any crime against the laws of state, except those of treason or murder, the court in its discretion, may: ...

2. Suspend the execution of the judgment at the time of judgment or at any time during the term of a sentence in the county jail and place the defendant on probation under such terms and conditions as it deems necessary and expedient; or

4. Suspend the execution of the judgment at any time during the first one hundred eighty (180) days of a sentence to the custody of the state board of correction. The court shall retain jurisdiction over the prisoner for the one hundred eighty (180) days...

This partly accounts for the variability in $N$ 's used in various analyses as those convicted but not yet sentenced are included in some analyses but not in others. The cases used in the various analyses change due to changes in missing data (see Figure 1 for a visual representation of this changing $N$ ). While 1,069 cases were convicted, some were pending final sentencing reducing the information for length of prison or probation sentencing. While 916 offenders had a prison sentence imposed, these include those sent to retained jurisdiction or having a withheld judgment or a suspended sentence and placed on probation. Each dependent variable analysis is independent of the others to maximize total $N$ for the analysis due to missing data for the independent variables.

\section{<<INSERT FIGURE 1 ABOUT HERE >>}




\section{Variables in this Analysis}

In collecting data for the annual census of CSA in the state, some data is readily available in the court records while other data has restricted access due to court mandated privacy issues. Much of the restricted information is data on the characteristics of the offender. The researchers were not allowed access to pre-sentence reports when collecting data. While every effort was made to glean information from the court transcripts, some variables were more difficult to obtain than others.

Potential independent variables are many but can be divided into three groups: (a) characteristics of the victim, (b) characteristics of the offender, and (c) characteristics of the offense. Characteristics of the victim include the victim's gender and age. Characteristics of the offender include the offender's age, education, occupation, and income. Characteristics of the offense include the age difference between the victim and offender, the relationship between the victim and offender, the closeness of the victim and offender, whether the crime was forced, number of charges, number of victims, urbanization, and whether the crime was amended to a non-sex crime. It should be noted that ethnicity of the offender or victim did not appear related to any of the dependent variables at the bivariate or multivariate levels in these data.

Dependent variables. Sentenced to prison was coded as 0 while sentenced to probation is coded as 1 . Total prison sentence was coded in months while a life sentence was coded as 600. Total prison sentence is use both for all offenders and for only those sent to prison. Probation as also coded in months with lifetime probation coded as 777.

Victim characteristics. Age of victim was coded in years. Gender of the victim was coded 0 for males and 1 for females.

Offender characteristics. Age of offender was coded in years. Education was initially coded in years but was dichotomized to less than high school coded as 0 and high school or more coded as 1 . Occupation was dichotomized into two groups, those with no or unskilled jobs coded as 0 and those with skilled or more prestigious jobs coded as 1. Data on income of the offenders were also extremely limited. Income was dichotomized into two groups, $\leq \$ 20,000$ annually coded as 0 vs. $>\$ 20,000$ annually coded as 1 .

Characteristics of the offense. CSA occurs in numerous places but for this analysis was dichotomized into those taking place in a residence coded as 0 vs. those in other locations coded as 1 . Idaho is a generally rural state with one predominately urban county. Those cases occurring in Ada County were coded as 0 while those in other counties coded as 1 . In all cases the offender was older than the victim, the age difference between the offender and victim were coded in years. With regard to the closeness of the offender and victim the coding ranges from 1 as not close to 4 as intimate. The relationship between the offender and the victim was dichotomized as those related to the victim through blood or marriage as 0 and those not related to the victim as 1 .

Level of force used in the abuse was coded as consensual (1), involuntary (2), and forced (3). No case with a victim under the age of 12 was coded as consensual. Number of charges was a count as was number of victims. Those with 0 victims consisted of those convicted of sex offender registration violations and those caught in internet sting operations.

Charges amended to non sexual abuse felonies were coded as 0 if not amended and 1 if amended. While there were a lengthy number of possible charges this variable was dichotomized as 0 for less serious charges and 1 for more serious charges. More serious changes include those that could include a possible life sentence. It should be noted that Lewd and Lascivious (a serious charge) was the most common charge but often amended to a lesser CSA charge through plea bargain.

Variables of interest not included in the analysis. There are a few variables for which data was available but for which no associations were found; they are included here for clarity. Sex of the offender was not associated with any other variables in the analysis. This is likely because the vast majority of offenders were male.

Ethnicity is another variable of interest to many as CSA normally takes place within ethnic groups. The vast majority of offenders and victims were white. 


\section{Statistical Analyses}

To understand the possible relationships between sentencing outcomes and the potential independent variables statistical analysis is started at the univariate level then at the bivariate level and then further refined in a series of multivariate analyses based on the characteristics of the dependent variable under analysis. At the univariate level all variables previously discussed are included while at the bivariate and multivariate levels only those associations that reach significance at least the .05 level are included.

\section{Results}

\section{Univariate Findings}

The 19 variables included in this analysis are nominal, ordinal and interval in nature. The nominal variables have been dichotomized so that they may be used in multivariate analysis and in some cases to minimize the effects of missing data for other ordinal or interval variables. Table 1 shows the central tendency, dispersion and $\mathrm{N}$ of each variable. For the dichotomized variables the Mean denotes the proportion of cases falling into category 1 . The most interesting features of these univariate findings are those variables with limited N's and those variables that are included in the table but will not be included in further analysis. As discussed above, some demographic characteristics of the offender are difficult to obtain. These include variables that might traditionally be seen as important in any criminal justice analysis (see endnote 2 for details). Additionally, and encouragingly variables often seen as sources of societal discrimination, ethnicity for example, do not appear to be involved in determining sentencing outcomes in this study.

\section{<<INSERT TABLE 1 ABOUT HERE >>}

\section{Bivariate Findings}

The significant bivariate correlations shown in Table 2 have an overlapping relationship between being sent to prison or probation, prison sentence for everyone, prison sentence for those actually sent to prison and the length of probation and the independent variables in this analysis. Some of the presumed independent variables are related to all 4 dependent variables while others are related to only 1 . There were 10 independent variables related to actually being sent to prison, 7 of which were related to one or more of the other dependent variables. Total prison sentence, offender age, victim age, and the age difference between the offender and victim were also related to being sent to prison. Less closeness between the offender and victim, more force used, and non-relative status were also related to going to prison. An increasing number of victims or charges and the lack of amendments to non-sex charges also increased the likelihood of going to prison.

Sixteen independent variables were related to the total prison sentence for all those convicted of CSA. Variables from all three characteristics (victim, offender, and offense) were related and in the expected direction. The age variables remained related in the same manner as with actually being sent to prison as did the variables for force, closeness, and numbers of victims and charges. Three variables not related to being sent to prison were related to total prison sentence for all convicted and include more offender characteristics, such as occupation and education, and an offense characteristic in the seriousness of the charge.

Eleven variables were related to the length of probation sentence and again include variables from all three characteristic types. Interestingly, the variables positively associated with prison sentencing were also positively associated with probation sentencing.

\section{<<INSERT TABLE 2 ABOUT HERE〉>}

\section{Multivariate Findings}

Some of the variables displayed in Table 2 are composite variables (i.e., made up of two other variables that were also in the bivariate analysis). For example, age difference was created by subtracting age of victim from age of offender. When these variables were all included in a multivariate analysis, some of them dropped out. The 
following analysis is thus based on only those that remained significant in combination. It should also be noted that Offender Income, a limited dichotomous variable, was excluded from some analysis as it reduced the total $N$ to such an extent that other independent variables were not significant.

Table 3 shows the binomial regression results for being sent to prison or probation. Several models were run using the 10 variables shown to have a bivariate relationship with being sent to prison. Only 5 variables were significant when included in the multivariate analysis. The addition of these 5 variables significantly improved the predictive model. The pseudo R square ${ }^{1}$ indicated that these 5 variables explained $20 \%$ to $27 \%$ of the variance in being sent to prison. Increases in age of offender, total number of charges, and total prison sentence all increased the odds of being sent to prison. The closeness between victim and offender and amending the charge to a non-sex crime both decreased the odds of going to prison.

Table 4 displays the linear regression results for both prison and probation sentencing. Only 4 of the original associated variables remained related to total prison sentence for all those convicted in the multiple regression analysis. Those with charges amended to a non-sex crime received a shorter sentence, while those with younger victims, those with more charges, and those with higher income received a longer sentence. When those who were actually sent to prison were looked at alone, the associations changed dramatically. Only one of the independent variables related when all convicted offenders were included remained significant (Victim Age), while three other variables emerged as significant. Those closer to the victim received a shorter sentence while those with more victims and greater age difference received longer sentences. ${ }^{2}$

Of the original independent variables related to probation length at the bivariate level, only 3 remained related in the multivariate analysis. These included prison sentence length, the urbanization of the county, and the level of force used. All the characteristics of the victim and offender fell out of the analysis, leaving only characteristics of the offense. Those convicted outside of Ada County and those who used more force tended to receive longer probation sentences. Of course, prison and probation lengths are related as the prison sentence received is positively related to the probation sentence received.

\section{$<<$ INSERT TABLES 3 AND 4 ABOUT HERE >>}

\section{Discussion}

While numerous variables were related to being sent to prison or probation and the length of sentence imposed at the bivariate level, many of these dropped out in a multivariate analysis. However, variables from all three characteristic types (victim, offender, and offense) remained in the analysis, showing that sending a convicted offender to prison and the length of the prison sentence is a complex process where information on a variety of characteristics are taken into account. It is encouraging to note that neither offender nor victim ethnicity was related to sentencing of convicted child sex offenders; while ethnicity might play a role earlier in the criminal justice process (Leiber \& Blowers, 2003), in the cases analyzed it did not appear to play a part post-conviction. However, it should be noted that the population of this state is very homogeneous (White), with the only large minority group being Hispanic. If the minority population was larger, there might have been a significant relationship. The gender of the victim, on the other hand, does appear to play a part in the sentencing outcome; this finding is consistent with other research (Curry, Lee, \& Rodriguez, 2004).

Probation sentencing seems to be affected by different variables than prison sentencing. Variables from all three characteristics predicted prison sentencing, but only characteristics of the offense predicted probation sentencing. This could be yet another funnel effect, in that those convicted on felony CSA are given a prison sentence by default and then the decision is made whether the individual will go to prison or probation and for how long. Total prison sentence for all those convicted is influenced by variables from all three characteristics (offender, victim, and offense). If the decision is to send the offender to prison, the sentence is influenced more by characteristics of the offense. If the decision is to send the offender to probation, the sentence is influenced by different characteristics of the offense. While we cannot say that justice is completely blind, it does appear that offense characteristics play a larger part in sentencing then characteristics of the offender or victim. More research is needed to confirm that characteristics of the offender and victim do not play significant roles in the process of sentencing outcomes. 
The findings here support past research on relationships in sex crimes (McCormick, Maric, Seto, \& Barbaree, 1998) in that offenders who were strangers or acquaintances were more likely to receive longer sentences. Our findings also support past research related to employment and sentencing (Nobiling, Spohn, \& DeLone, 1998) showing that socioeconomic factors affect sentencing outcomes. The effects of the urban/rural divide shown in this study also replicate past work on urban/rural differences (Myers \& Talarico, 1986).

\section{Limitations}

This research has several limitations, including significant missing data. The lack of data on variables such as offender income, employment, and prior criminal history likely reduced the $N$ of the analysis, resulting in a loss of statistical power. The lack of any knowledge of prior offenses and the very limited information on the demographics of the offenders means spuriousness could be an issue. Other research has shown that fewer than $10 \%$ of child sex offenders will offend more than once and only a very small percentage will reoffend more than twice (Patrick \& Marsh, 2009), but lack of this criminal history for this group of offenders casts a shadow on this work as those with prior convictions can be expected to receive longer sentences and are more likely to be sent to prison.

A second limitation is the fact that while the data used for this analysis is from a census of all cases, the collection of the data so soon after the end of the fiscal year limits the number of cases reaching final disposition. This limitation is mitigated somewhat by prior research showing those reaching final disposition and those not reaching final disposition during the fiscal year are not significantly different (Patrick \& Marsh, 2009). Some of the cases in this analysis were pending sentencing, but only those convicted were used.

A third limitation may be the increased possibility of committing a Type I error due to the large number of bivariate correlations run. While all reported correlations were significant at the .05 level or better, there is a possibility that a few of the correlations are the result of rejecting the null hypothesis when in fact it is true. This potential problem is mitigated somewhat in the multivariate analysis due to many of the bivariate associations dropping out. While in the bivariate analysis 47 of the 68 correlations run were significant, the individual multivariate analyses contained no more than 5 significant associations.

\section{Conclusions}

Sentencing outcomes are important in understanding the criminal justice system. This research attempts to shed light on a small part of this process and shows strongly the need for more research. While characteristics of the offender, victim, and offense all seem to affect sentencing outcomes to some degree, the characteristics of the offense seem to play the largest part. This would seem to suggest that the circumstances of the offense influence sentencing more that characteristics of the victim or offender. This research also seems to show that the sentencing process in the criminal justice system is working, at least as it pertains to these data, in that those committing more serious crimes were given longer sentences and actually sent to prison for their crime. 


\section{Endnotes}

${ }^{1}$ The analysis of multivariate data using nominal or ordinal dependent variables has been a limitation in the social sciences when compared to the analysis of interval/ratio dependent variables. While the analysis of Log-Odds or log linear analysis has been round for decades, it has not begun to reached main stream use until statistical programs and methods of analysis have developed that are comparable to the well understood regression analysis. Part of this comparability is the development of Pseudo- $R$ Square. The Pseudo- $R$ Square is not based on percentage of variance explained as $R$-Square is but is comparable in interpretation as it is based on the percent of the change in the odds ratio explained. As odds changes is the key factor in log linear analysis much as the beta's are a key factor in regression, the Pseudo- $R$ Square in comparable to the $R$-Square but as it is not based on Variance it cannot be called $R$-Square.

${ }^{2}$ Due to the limitations of the data collection process, some characteristics of the offender have limited availability. Income is one of these offender characteristics. While correlations at the bivariate analysis showed that income was related to sentencing, when included in the multivariate analysis the $N$ dropped so much as to make none of the variables significant. Not including income resulted in a larger $N$ and allowed more variables to remain significant in the multivariate analysis. Because of its exclusion, income cannot be ruled out as characteristic influencing sentencing outcomes. 


\section{References}

Austin, J., \& Krisberg, B. (1985). Incarceration in the United States: The extent and future of the problem. The Annals of the American Academy of Political and Social Science, 478, 15-30.

Bonta, J. (2007). Offender risk assessment and sentencing. Canadian Journal of Criminology and Criminal Justice, 49(4), 519-529.

Chiricos, T., Barrick, K., Bales, W., \& Bontrager, S. (2007). The labeling of convicted felons and its consequences for recidivism. Criminology, 45(3), 547-581.

Cohen, M., \& Jeglic, E. L. (2007). Sex offender legislation in the United States: What do we know? International Journal of Offender Therapy and Comparative Criminology, 51(4), 369-383.

Crow, M. S., \& Gertz, M. (2008). Sentencing policy and disparity: Guidelines and the influence of legal and democratic subcultures. Journal of Criminal Justice, 36(4), 362-371.

Cullen, B. J., Smith, P. H., Funk, J. B., \& Haaf, R. A. (2000). A matched cohort comparison of a criminal justice system's response to child sexual abuse: A profile of perpetrators. Child Abuse and Neglect, 24(4), 569-577.

Curry, T. R., Lee, G., \& Rodriguez, S. F. (2004). Does victim gender increase sentence severity? Further explorations of gender dynamics and sentencing outcomes. Crime \& Delinquency, 50(3), 319-343.

Demuth, S., \& Steffensmeier, D. (2004). Ethnicity effects on sentence outcomes in large urban courts: Comparisons among White, Black, and Hispanic defendants. Social Science Quarterly, 85(4), 994-1011.

Doob, A. N., \& Webster, C. M. (2003). Sentence severity and crime: Accepting the null hypothesis. Crime and Justice, 30, 143-195.

Faller, K. C., Birdsall, W. C., Vandervort, F., \& Henry, J. (2006). Can the punishment fit the crime when suspects confess child sexual abuse? Child Abuse \& Neglect, 30(7), 815-827.

Greenfeld, L. A., Beck, A., \& Gilliard, D. (1996). Prisons: Population trends and key issues for management. Criminal Justice Review, 21(1), 4-20.

Idaho Statutes: 19-2601. Suspension of judgment and sentence and parole offenders. Retrieved 9/19/09 from, http://legislature.idaho.gov/idstat/Title19/T19CH26SECT19-2601.htm

Kovandzic, T. V., Sloan, J. J. III, \& Vieraitis, L. M. (2004). "Striking out" as crime reduction policy: The impact of "three strikes" laws on crime rates in U.S. cities. Justice Quarterly, 21(2), 207-239.

Leiber, M. J., \& Blowers, A. N. (2003). Race and misdemeanor sentencing. Criminal Justice Policy Review, 14(4), 464-485.

Loza, W., MacTavish, A., \& Loza-Fanous, A. (2007). A nine-year follow-up study on the predictive validity of the self-appraisal questionnaire for predicting violent and nonviolent recidivism. Journal of Interpersonal Violence, 22(9), 1144-1155.

Lucken, K., \& Bales, W. (2008). Florida's sexually violent predator program. Crime \& Delinquency, 54(1), 95-127.

Marsh, R., Patrick, S. \& Hopfenbeck, T. (2001-2007). Reports on prosecution of child sexual abuse. Retrieved 9/19/09 from, http://www2.state.id.us/ag/sexual_prosecution_reports/reports_index.htm

Marvell, T. B., \& Moody, C. E. (1996). Determinate sentencing and abolishing parole: The long-term impacts on prisons and crime. Criminology, 34(1), 107-128.

Mauer, M. (2007). The hidden problem of time served in prison. Social Research, 74(2), 701-706.

McCormick, J. S., Maric, A., Seto, M. C., \& Barbaree, H. E. (1998). Relationship to victim predicts sentence length in sexual assault cases. Journal of Interpersonal Violence, 13(3), 413-420.

Myers, M. A., \& Talarico, S. M. (1986). Urban justice, rural injustice? urbanization and its effect on sentencing. Criminology, 24(2), 367-392.

Nobiling, T., Spohn, C., \& DeLone, M. (1998). A tale of two counties: Unemployment and sentence severity. Justice Quarterly, 15(3), 459-485.

Patrick, S., \& Marsh, R. (2009). Recidivism among child sexual abusers: Initial results of a 13 year longitudinal random sample. Journal of Child Sexual Abuse, 18(2), 123-136.

Patterson, E. J., \& Preston, S. H. (2008). Estimating mean length of stay in prison: Methods and applications. Journal of Quantitative Criminology, 24(1), 33-49.

Petrunik, M., \& Deutschmann, L. (2008). The exclusion-inclusion spectrum in state and community response to sex offenders in Anglo-American and European jurisdictions. International Journal of Offender Therapy and Comparative Criminology, 52(5), 499-519.

Quinn, J. F., Forsyth, C. J., \& Mullen-Quinn, C. (2004). Societal reaction to sex offenders: A review of the origins and results of the myths surrounding their crimes and treatment amenability. Deviant Behavior, 25(3), 215 232. 
This is an electronic version of an article published in Journal of Child Sexual Abuse, 20(1). Journal of Child Sexual Abuse is available online at: http://www.informaworld.com/smpp. DOI: 10.1080/10538712.2011.541356

Schlager, M. D., \& Robbins, K. (2008). Does parole work?-revisited: Reframing the discussion of the impact of postprison supervision on offender outcome. The Prison Journal, 88(2), 234-251.

Ulmer, J. T., Kurlychek, M. C., \& Kramer, J. H. (2007). Prosecutorial discretion and the imposition of mandatory minimum sentences. Journal of Research in Crime and Delinquency, 44(4), 427-458.

Weiman, D. F. (2007). Barriers to prisoners' reentry into the labor market and the social costs of recidivism. Social Research, 74(2), 575-611.

Whitman, J. Q. (2007). What happened to Tocqueville's America? Social Research, 74(2), 251-268.

Zatz, M. S., \& Hagan, J. (1985). Crime, time, and punishment: An exploration of selection bias in sentencing research. Journal of Quantitative Criminology, 1(1), 103-126. 


\section{Figure 1: Variable N's in Analyses}

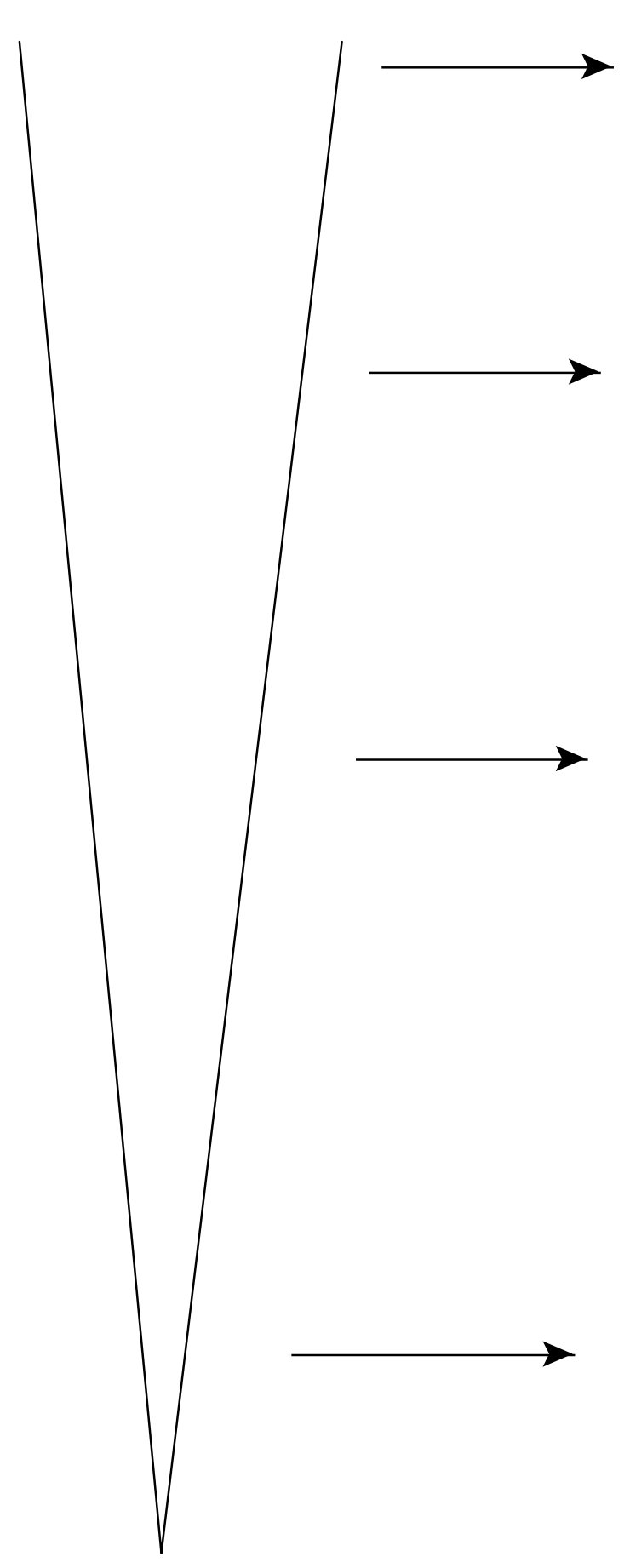

1069: Total number of Original Cases.

916 Total number of Cases with Completed Sentencing information.

815 Total number of cases either Sent to Prison (331) or Set to Probation (484).

For multivariate analysis the $\mathrm{N}$ ranges from 277 for analyses including Income to 815 for analyses with no missing values. 
Table 1

Descriptive Statistics of Dependent and Independent Variables

\begin{tabular}{|c|c|c|c|}
\hline Variable & Central Tendency & Dispersion & $\mathbf{N}$ \\
\hline Sent to Prison or Probation & Mean $=.455$ & Range $=0-1$ & 1069 \\
\hline Total Prison Sentence & Mean $=147.14$ & $\mathrm{SD}=147.79$ & 916 \\
\hline Total Sentence for those Sent to Prison & Mean $=204.1$ & $\mathrm{SD}=201.9$ & 331 \\
\hline Length of Probation & Mean $=76.54$ & $\mathrm{SD}=58.07$ & 484 \\
\hline Victim Age & Mean $=12.99$ & $\mathrm{SD}=3.60$ & 990 \\
\hline Victim Gender & Mean $=.099$ & Range $=0-1$ & 990 \\
\hline Offender Age & Mean $=32.25$ & $\mathrm{SD}=12.26$ & 1069 \\
\hline Offender Education & Mean $=11.26$ & $\mathrm{SD}=1.99$ & 423 \\
\hline Offender Education Dichotomized & Mean $=.560$ & Range $=0-1$ & 423 \\
\hline Offender Job Status Dichotomized & Mean $=.399$ & Range $=0-1$ & 407 \\
\hline Offender Income Dichotomized & Mean $=.292$ & Range $=0-1$ & 277 \\
\hline Location of Offense Dichotomized & Mean $=.237$ & Range $=0-1$ & 837 \\
\hline Age Difference Between Offender and Victim & Mean $=18.26$ & $\mathrm{SD}=13.63$ & 980 \\
\hline Closeness of Offender and Victim & Median $=3$ & Range $=3$ & 812 \\
\hline Level of Forced & Median $=2$ & Range $=2$ & 771 \\
\hline Total Number of Charges & Mean $=1.68$ & $\mathrm{SD}=1.52$ & 1065 \\
\hline Total Number of Victims & Mean $=.98$ & $\mathrm{SD}=.57$ & 1063 \\
\hline Abuse Amended to Non-Sex Crime & Mean $=.198$ & Range $=0-1$ & 1069 \\
\hline Relationship of Offender to Victim Dichot. & Mean $=.77$ & Range $=0-1$ & 805 \\
\hline Seriousness of Charge Dichotomized & Mean $=.748$ & Range $=0-1$ & 1003 \\
\hline Region of Abuse, Urban or Rural & Mean $=.84$ & Range $=0-1$ & 1069 \\
\hline \multicolumn{4}{|l|}{ Variables Not in the Analysis } \\
\hline Sex of Offender & Mean $=.037$ & Range $=0-1$ & 1069 \\
\hline Ethnicity of Offender & Mode $=$ White $(82.9 \%)$ & Range $=4$ & 1069 \\
\hline Ethnicity of Victim & Mode $=$ White $(89.8 \%)$ & Range $=4$ & 803 \\
\hline
\end{tabular}


Table 2

Correlations (Significant at .05 or better)

\begin{tabular}{|c|c|c|c|c|}
\hline & Actually sent to Prison & $\begin{array}{l}\text { Total Prison Sentence for } \\
\text { All Convicted }\end{array}$ & $\begin{array}{l}\text { Total Sentence for those Sent to } \\
\text { Prison }\end{array}$ & Probation Length \\
\hline Total Prison Sentence & .30 & & & .54 \\
\hline Offender Age & .17 & .15 & .16 & \\
\hline Age Difference Off/Victim & .28 & .28 & .25 & .15 \\
\hline Victim Age & -.02 & -.25 & -.28 & -.23 \\
\hline Closeness Offender/Victim & -.21 & -.20 & -.23 & -.12 \\
\hline Abuse Forced & .17 & .21 & .18 & .14 \\
\hline Total Number of Charges & .15 & .20 & .21 & .12 \\
\hline Total Number of Victims & .17 & .34 & .33 & .18 \\
\hline Amended to Non-Sex Crime & -.22 & -.12 & & -.29 \\
\hline Relative Offender/Victim & -.19 & -.15 & & -.18 \\
\hline Offender Job & & .16 & .29 & \\
\hline Offender Income & & .25 & .50 & \\
\hline Victim Gender & & -.07 & & \\
\hline Seriousness of Charge & & .06 & & \\
\hline Offender Education & & -.24 & & \\
\hline Urban/Rural & & .07 & & .18 \\
\hline
\end{tabular}


Table 3

Binomial Regression

Dependent variable Sent To Prison or Probation

Cox and Snell R Square $=.205$

Nagelkerke R Square $=.274$

Chi Square $=104.426$ Sig. $=.<.001$

Sig.

\section{Constant}

Offender Age

$-2.122$

$<.001$

Total Charges

.022

.026

Closeness of Offender/Victim

.223

.027

Amended to Non-Sex Crime

$-.223$

.025

Total Prison Sentence

1.031

.002

.006
$<.001$ 
Table 4

Regression

\begin{tabular}{|c|c|c|c|c|c|c|c|c|c|}
\hline \multicolumn{4}{|c|}{ Total Prison Sentence for All Convicted } & \multicolumn{3}{|c|}{ Total Prison Sentence for Those Sent to Prison } & \multicolumn{3}{|c|}{ Length of Probation } \\
\hline \multirow[t]{2}{*}{ R Square .17} & \multirow{2}{*}{$\begin{array}{l}\mathrm{F}=9.8 \\
\text { Beta }\end{array}$} & \multicolumn{2}{|c|}{ Sig. $=<.001$} & R Square $=.20$ & $F=14.4$ & Sig. $=<.001$ & \multirow{2}{*}{$\begin{array}{c}\text { R Square } .296 \\
\text { Beta }\end{array}$} & \multirow{2}{*}{$\begin{array}{r}\text { F } 25.2 \\
\text { SD Beta }\end{array}$} & \multirow{2}{*}{$\begin{array}{l}\text { Sig. }<.001 \\
\text { Sig. }\end{array}$} \\
\hline & & SD Beta & Sig. & Beta & SD Beta & Sig. & & & \\
\hline Constant & 215.701 & & $<.001$ & 230.037 & & .002 & 30.58 & & $<.001$ \\
\hline Amended & -52.399 & -.143 & .032 & & & & & & \\
\hline Victim Age & -7.542 & -.205 & .002 & -6.997 & -.135 & .048 & & & \\
\hline Total Charges & 10.679 & .191 & .004 & & & & & & \\
\hline Income2 & 60.693 & .234 & $<.001$ & & & & & & \\
\hline Close & & & & -27.281 & -.151 & .014 & & & \\
\hline Total Victims & & & & 81.049 & .258 & $<.001$ & & & \\
\hline Age & & & & 2.176 & .148 & .031 & & & \\
\hline \multicolumn{10}{|l|}{ Difference } \\
\hline Tot Prison & & & & & & & .32 & .41 & $<.001$ \\
\hline \multicolumn{10}{|l|}{ Sentence } \\
\hline Urban & & & & & & & 34.47 & .23 & $<.001$ \\
\hline Abuse Forced & & & & & & & 11.49 & .17 & $<.001$ \\
\hline
\end{tabular}

